\title{
Relações Históricas entre a Educação Ambiental e a Participação Social
}

\author{
Marina Battistetti Festozo* \\ Ricardo Campos Queixas** \\ Antonio Fernandes Nascimento Junior ${ }^{* * *}$ \\ Marilia Freitas de Campos Tozoni-Reis ${ }^{* * * *}$
}

\section{Resumo}

Recorremos à história para pesquisar as relações entre movimentações sociais e a concepção crítica da Educação Ambiental brasileira. Tomamos o materialismo histórico-dialético como referencial teórico-metodológico. Os dados resultam de pesquisa bibliográfica e de campo, entrevistando personagens da área de história ambiental e do ambientalismo europeu. Nossas pesquisas indicam que, em meio aos novos movimentos sociais, o movimento ambientalista assume novas críticas, ao uso de energia nuclear, à cultura política, aos modos de vida, etc. Estes movimentos contribuem com o aprimoramento da participação da sociedade e, portanto, com a sua formação política. O Brasil, apesar da longa história de exploração e tolhido por ditaduras, com o tempo, sintetiza ideais revolucionários locais e estrangeiros e se torna solo fecundo a um movimento crítico, inclusive na educação. A Educação Ambiental se fortalece junto a este movimento, articulando assim a questão ambiental à justiça, participação, emancipação social e sustentabilidade.

Palavras-chave: Educação Ambiental Brasileira; Movimentos Sociais; Participação.

\footnotetext{
* Doutora em Educação para a Ciência, pela Faculdade de Ciências da UNESP-Bauru/SP. Professora Adjunta do Departamento de Biologia da Universidade Federal de Lavras - UFLA/MG. E-mail: mbfestozo@hotmail.com

** Bacharel em Educação Física pela Universidade Estadual de Campinas - UNICAMP. E-mail: ricardocqueixas@gmail.com

*** Doutor em Educação para a Ciência, pela Faculdade de Ciências da UNESP-Bauru/SP. Professor Adjunto do Departamento de Biologia da Universidade Federal de Lavras - UFLA/MG. E-mail: toni_nascimento@ yahoo.com.br

**** Doutora em Educação, pela Universidade Estadual de Campinas - UNICAMP. Livre-Docente em Educação pela Universidade Estadual Paulista - UNESP. Professora Aposentada da Universidade Estadual Paulista - UNESP, junto ao Departamento de Educação do IB, Botucatu/SP. Professora do Programa de Pós-graduação em Educação para a Ciência na FC, UNESP-Bauru/SP. E-mail: mariliatozoni@uol.com.br
} 


\section{Historical Relations Between Environmental Education and Social Participation}

\section{Relaciones Históricas entre la Educación Ambiental y la Participación Social}

\begin{abstract}
We turn to history to investigate the relationships between social movements and the critical conception of Brazilian Environmental Education. We take historical-dialectical materialism as a theoretical-methodological reference. The data are the result of bibliographical and field research, interviewing characters of environmental history and European environmentalism areas. Our research indicates that, among the new social movements, the environmental movement assumes new criticisms, such as the use of nuclear energy, political culture, ways of life, etc. These movements contribute to the improvement of society's participation and, therefore, to its political formation. Brazil, despite its long history of exploitation and stunted by dictatorships, over time synthesizes local and foreign revolutionary ideals and becomes fertile ground for a critical movement, including education. Environmental Education strengthens along with this movement, articulating the environmental issue to justice, participation, social emancipation and sustainability.
\end{abstract}

Keywords: Brazilian Environmental Education; Social Movements; Participation.

\section{Resumen}

Recurrimos a la historia para investigar las relaciones entre movimientos sociales y la concepción crítica de la Educación Ambiental brasileña. En partida, tomamos el materialismo histórico-dialéctico como referencial teórico-metodológico. Los datos resultan de investigación bibliográfica y de campo, con versiones directas de personajes del área de historia ambiental y del ambientalismo. Nuestras encuestas indican que, en medio de los nuevos movimientos sociales, el ambientalista asume nuevas críticas, antinucleares, la cultura política, los modos de vida. Estos contribuyen con el perfeccionamiento de participación de la sociedad y, por lo tanto, con su formación política. Brasil aunque la larga historia de explotación y tullido por dictaduras, con el tiempo, sintetiza ideales revolucionarios locales y extranjeros, conviertendose en suelo fecundo a un movimiento crítico, incluso en la educación. La Educación Ambiental si fortalece con este movimiento, articulandose así la cuestión ambiental junto con la justicia, participación, emancipación social y sustentabilidad.

Palabras clave: Educación Ambiental brasileña; Movimientos Sociales; Participación. 


\section{Introdução}

A educação, como fenômeno peculiar humano, é a condição que possibilita a um membro da espécie humana tornar-se homem, não apenas para se inserir em seu contexto social, reproduzindo-o, mas, sobretudo, para lhe dar condições de refletir sobre os determinantes históricos e os rumos que a sociedade vem tomando, de modo a participar por meio do trabalho educativo do processo de criação desta sociedade e do gênero humano, almejando melhores condições de vida ao conjunto das pessoas. Assim, participar implica em humanizar-se, mas a participação, ela mesma também possibilita esta humanização. Neste sentido, Trein (2012, p. 309-310) afirma:

Se vivemos em condições de exploração e alienação tanto da natureza quanto dos seres humanos, como forma necessária de reprodução do capital, se faz necessário para a superação destas uma ação consistente dos sujeitos. Isso implica em uma mudança radical, em uma nova forma de ser no mundo, reestruturando o metabolismo da reprodução material e social da vida.

Neste sentido, a intervenção transformadora coerente implica em compreender as condições reais de vida em suas múltiplas questões, pelo exercício do pensamento. Esta questão se coloca como desafio para a Educação Ambiental, exigindo a articulação dialética entre teoria e prática social, reflexão e ação e ainda como afirma Novicki (2007, p. 136) "entre consciência ambiental e participação na esfera pública". Uma sociedade civil que não se organiza participativamente não cria condições objetivas de defesa dos seus interesses, além de ter reduzida sua compreensão crítica frente à realidade. É importante ter claro que a participação não é dada, mas precisa ser conquistada, o que implica escolhas, assumir posturas e responsabilidades.

As relações entre Educação Ambiental e a participação social são estudadas há tempos no Brasil, tanto tomadas como tema de preocupação, mas também como modalidade de pesquisa, por meio da pesquisa-participativa ou pesquisa-ação-participativa em educação ambiental (DEMO, 2001, JACOBI, 2005, NOVICKI, 2007, TOZONI-REIS, 2007, entre outros).
Contudo, historicamente estas relações nem sempre ocorreram e/ou se evidenciaram, a temática ambiental por longo tempo foi compreendida como própria de movimentos burgueses, de contemplação da natureza no seu tempo livre, portanto, longe das preocupações relativas às questões sociais, políticas, econômicas, etc., Em meio a um rico mosaico de "Educações Ambientais", há ainda hoje no Brasil e no exterior, linhas cujas compreensões e atuações estão afastadas das questões sociais, dedicando-se ao preservacionismo e ao ensino de práticas individuais, idealizando comportamentos "ecologicamente corretos".

Na história a transformação das práxis educativas e ambientais em direção a uma abordagem mais crítica, que considera a problemática ambiental como inerente ao nosso modo de viver e se desenvolver (VIOLA, VIEIRA, 1992) - intrinsecamente ligada às questões sociais -, tem trajetória própria, um caminho em que convergem contribuições de diferentes áreas do conhecimento, com destaque para as ciências humanas e ambientais.

Neste artigo, recorremos à história para identificar elementos da concepção crítica da Educação Ambiental brasileira na participação e movimentações sociais, especialmente da década de 60 , no Brasil e exterior. Para isso, buscamos informações sobre as manifestações: das mais dispersas às mais organizadas e cristalizadas em movimentos sociais.

Tomamos o materialismo histórico-dialético como referencial teórico-metodológico de interpretação da realidade. As informações e análises aqui trazidas resultam de pesquisa bibliográfica e de campo, realizadas por ocasião de estágio de doutoramento sanduíche na Bélgica, no ano de $2013^{1}$. Assim, além da pesquisa realizada em publicações sobre os movimentos sociais, especialmente o ambientalista, foram entrevistados (entrevistas semiabertas) ativistas, professores e pesquisadores da área, na Bélgica e na França. O esforço de coleta de dados pretendeu contribuir com os objetivos deste estudo, mas assumimos um recorte, pois sabemos que a questão é vasta e são inúmeras as análises que podem ser construídas sobre as relações históricas sobre a participação da 
população, sua organização em movimentos sociais e a educação ambiental.

\section{Participação social e meio ambiente na história}

Embora haja uma tendência em se acreditar que a preocupação ambiental é decorrente do crescimento industrial que a sociedade vivencia nos séculos XVIII e XIX em alguns países da Europa e a partir da metade do século XX no Brasil, Loureiro (2003) relata a existência de documentos do século XVII que já se referem à preocupação ambiental no mundo, embora não identificada como "ambientalista" ou "ecologista". No Brasil, já no século XVI, no período da colonização, no livro "História do Brasil" de Frei Vicente Salvador, há denúncias da exploração em larga escala do pau-brasil feita pelos colonizadores portugueses. Loureiro (2003) destaca esta obra como precursora do movimento ambientalista brasileiro.

Contudo, é mesmo a partir do século XIX que a questão ambiental ganha relevância e distinção, gerando movimentações mais organizadas em sua defesa (BOURG, 2016; LOUREIRO, 2003), sendo importante distinguirmos as origens das preocupações ambientalistas, principalmente no século XIX na Europa, Estados Unidos e Brasil e as origens do ambientalismo como movimento social e político, na segunda metade do século XX.

A consciência ambiental e as consequentes movimentações ganham proeminência quase concomitantemente nos diferentes cantos do mundo e parecem ter ocorrido por motivos diferentes: por exemplo, nos Estados Unidos, segundo Bourg (2016), o maior impulso foi dado pelo impacto humano na natureza devido ao desmatamento massivo e acelerado, na segunda metade do século XIX. Em resposta, norte-americanos se organizam em torno das causas do preservacionismo, conservacionismo e reflorestamento. $\mathrm{Na}$ Europa, a devastação florestal era uma questão muito antiga, um problema crônico na histórica das sociedades. Mas, houve outro fator que fez repercutir e motivar a consciência ambiental e movimentações sociais: a industrialização, que deteriorava as paisagens e afetava as pessoas, assim como toda a vida no entorno das indústrias² (BOURG, 2016). Já no Brasil, o início se dá em consequência da exploração da terra, tanto pela extração vegetal quanto mineral, mas também em consequência da exploração dos trabalhadores, realizações dos colonizadores europeus, que também ocorreu em outros países colônias de exploração (GALEANO, 2011).

Se uma ou outra questão tiveram maior contribuição em fazer avançar a conscientização ambiental das sociedades, elas não foram as únicas, os impactos que afetavam a vida das pessoas, os estudos, pesquisas e a sua divulgação foram pouco a pouco possibilitando o aprofundamento na compreensão da importância das questões ambientais. As entidades ambientalistas que começavam a atuar contribuíram para isso.

Nosso entrevistado, o professor Serusiaux ${ }^{3}$, afirma que do final do século XIX até a primeira Guerra Mundial, na França e na Inglaterra existiam organizações que trabalhavam em defesa das aves, que tinham suas penas e plumas usadas nas vestimentas e acessórios das mulheres nobres e burguesas. Loureiro (2003) relembra também da importância do grupo inglês "Commons, Foot-paths and Open Spaces Preservation Society", tido como a primeira entidade declaradamente ambientalista, em 1865, atuando na defesa das baleias, entre outras pautas. Serusiaux ainda identifica o perfil das entidades ambientalistas neste momento histórico, que tinham na defesa de problemas ambientais pontuais sua principal luta, sendo comum a defesa e preservação de uma ou outra espécie em específico. Orellana e Fateux (2007) também corroboram esta análise a respeito do perfil do então"nascente" movimento ambientalista: centrado em atitudes preservacionistas de espécies ameaçadas e/ou na gestão racional da natureza. Podemos observar também que, nos dias de hoje, certas temáticas deixaram de ser motivo de preocupação e que algumas destas entidades, com o tempo ampliam e diversificam sua atuação, se tornando fortes entidades ambientalistas.

No século XIX ocorre, portanto, o desenvolvimento de denúncias, produção de conhecimento científico e até mesmo de leis que tematizavam o ambiente (BOURG, 2016). Mas, no início do século XX, ocorre a $1^{\text {a }}$ Guerra Mundial... Neste contexto, destacamos a fala da profes- 
sora Parmentier ${ }^{4}$ que afirma haver um enorme "vácuo" na organização das informações relativas à história ambiental, de seus movimentos e relações com as sociedades - especialmente trabalhos de análise - desde a $1^{\text {a }}$ Guerra Mundial até os dias de hoje. Há, porém, muitos dados documentais, ainda pouco organizados. É, portanto, uma centena de anos sem reflexões mais profundas destes fenômenos e as influências destes na educação ambiental, questões que merecem estas análises. Não há nenhum relato de nossos entrevistados sobre as questões ambientalistas no período do início da $1^{\text {a }}$ Guerra até

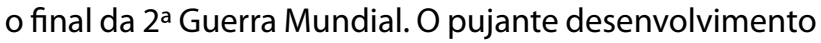
teórico e prático da questão ambiental aquieta-se neste período.

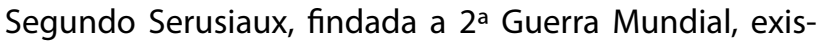
tiam grupos ambientalistas que atuavam em prol da conservação da natureza, não se voltando, contudo, a outras questões ambientais como a poluição, fontes energéticas, resíduos industriais e domésticos. Estes grupos tinham em comum alguns princípios e características (ser associativa, moralizadora e científica) e constituídos principalmente por indivíduos da classe média. Havia também, outras associações que tinham interesse pela defesa das paisagens, em geral, associavam-se pessoas da classe mais favorecida (como, por exemplo, empresários e donos de indústrias).

Mas, nas décadas que se seguiram ao fim da $2^{\text {a Guerra, }}$ sobretudo a partir de 60 , a questão ambiental começa a ganhar novos contornos, repercussão e amplitude, envolvendo outros atores e, segundo o professor entrevistado Yvan Carlot ${ }^{5}$, em sintonia com outras movimentações sociais de questionamento e contestação à época.

Os militantes ambientalistas e antinucleares estavam muito atentos aos ataques crescentes ao planeta; os militantes pela paz e pela não violência promoviam alternativas para resolver os conflitos; as feministas batalhavam por igualdade real entre mulheres e homens; os movimentos pelos direitos humanos e a liberdade resistiam aos regimes autoritários e ditatoriais; os movimentos de solidariedade com os países de "terceiro mundo" condenavam a colonização e reivindicam relações econômicas mais equilibradas entre Norte e Sul; indivíduos e grupos se engajavam contra a pobreza e pela justiça social no seio de nossas próprias sociedades (ETOPIA, 2006, tradução livre). Muitos são os autores que indicam o florescimento de diversas movimentações sociais contestatórias que de certa forma, por serem contemporâneas, se associam nesta fase histórica:

... quando do impacto das tecnologias de guerra, cuja utilização de energia nuclear (as explosões de Hiroshima e Nagasaki, por exemplo) e dos produtos químicos de efeitos devastadores (com destaque para os da guerra do Vietnam) e as catástrofes ecológicas (...) fazem levantar-se uma poderosa corrente de protestos. A partir deste mesmo contexto e paralelamente à onda pela conservação e proteção da natureza (a contestação ecológica), crescem os movimentos pacifistas e antirracistas, a revolta da juventude ocidental explode, a contracultura se manifesta (ORELLANA E FAUTEUX, 2007, p. 02).

Neste contexto, é importante compreender as bases que se assentavam tais enfrentamentos. Dupret ${ }^{6}$, durante entrevista nos dá um panorama geral: na Europa do século XIX e XX foram muitas as lutas por melhores condições de trabalho. Fazendo frente à burguesia, houve o crescimento do movimento socialista, dos sindicatos e cooperativas. Conquistou-se diversos direitos sociais, o voto acessível a todos, o desenvolvimento de pequenos comércios e mercearias nas cidades, a instauração do estado de bem estar social; mas também se observou abuso de poder, corrupção, a colonização dos sindicatos pelo partido socialista e, na segunda metade do século $X X$, vemos a decadência de um regime mais voltado ao bem estar da população e as mudanças no sistema de produção social em curso. Assim, burgueses e cristãos retomam, na década de 60, parte do poder perdido. Dupret afirma que eram voltados ao crescimento econômico, mas sociologicamente senis: "seu programa estava atrás e não à frente". Em meio a este cenário, surgem diferentes movimentações sociais antiburguesas (de operários com lideranças intelectuais, artistas, etc.), com características peculiares, contudo, têm em comum a crítica à forma como a sociedade se reorganizava, às regras, hábitos, códigos sociais e convenções, a posição da então 
classe que vinha se consolidando novamente no poder, à má distribuição de renda, à racionalidade mecanicista dominante (SEVCENKO, 2006, BRILLANT, 2008).

\section{Contestações dos anos 60 , os movimentos so- ciais europeus e a questão ambiental}

Em meio a este rico aglomerado de movimentos sociais, buscamos, portanto, compreender a natureza e construção histórica do movimento ambientalista, onde Loureiro (2003) e Carvalho (2004) afirmam que a educação ambiental brasileira parece ter suas raízes. Estes movimentos foram largamente influenciados pelo conjunto da prática social e da ideologia da década de 60, bem como também a modificaram: a cultura política, os modos de vida, propiciando o desenvolvimento de uma contracultura, mais crítica e participativa (FRANK, 2008). Entendemos a necessidade de levar em consideração que estes movimentos ocorreram não só na Europa, mas em diferentes localidades, inclusive no Brasil, sobre os quais nos aprofundaremos adiante.

As movimentações se iniciam com contestações comuns a diversos grupos, menos organizadas e só posteriormente, em fase mais avançada, vão gerar reivindicações e também se organizar de maneira mais institucionalizada. Na Europa este foi um momento de importante abertura ao diálogo social entre países, com a mobilização dos estudantes e posteriormente da sociedade de forma mais ampla, adentrando inclusive o seio familiar. Eram manifestantes, militantes, grevistas e também uma "maioria silenciosa" (DREYFUS-ARMAND, 2008). Seu estopim ocorre de maio até junho de 68 numa greve geral.

Mas, como as ideias revolucionárias chegam à população? Segundo Trebitsch (2008), grande parte das ideias progressistas tem suas origens teóricas na revisão do marxismo e inspiração em Hegel, Freud e Nietzsche, Trotski, Adorno, Reich, Marcuse, Rudi Dutschke, Guy Debord, Henri Lefebvre, Lukàcs etc., que se encontrava constantemente em linguagem mais simples, podendo ser assimilada. Circulavam por meio de revistas organizadas pelos pensadores críticos, coleções de livros de bolso a preços acessíveis, seminários e grupos de trabalho disseminando as ideias dos pequenos grupos intelectualizados para a juventude universitária. Tem importância também o tráfego de informações por meio de pessoas que circulavam entre os diferentes países.

As críticas à vida cotidiana e à modernidade deram força à emergência de um "movimento alternativo", a partir do qual se destaca, entre outros, o tema da "liberação sexual" (IDEM, p. 86), que se sobressai dado o desenvolvimento do movimento feminista nos anos anteriores: a luta e a conquista do direito de voto feminino em 1945 na França, poder exercer uma atividade profissional sem consentimento do marido, em 1965, e o direito à contracepção, em 1967. Estas questões foram essenciais para modificação da vida cotidiana e para que as mulheres pudessem avançar na conquista de direitos iguais. Obras como a Revolução Sexual de Reich (1936) e O segundo sexo de Beauvoir (1949) tiveram papel essencial nesta veiculação. Alguns autores discutem o fato de a sexualidade ser forte alavanca para a divulgação do pensamento crítico. Mas, por que especificamente a questão sexual possibilitou esta propagação? Brillant (2008, p. 102), inspirado pelas ideias de Nora (1989) conjectura: a sexualidade é a linguagem mais compreensível da alienação. Ela torna compreensíveis as misérias da sociedade, "a verdade alienante das relações sociais... do caráter repressivo da sociedade e de suas instituições".

Loureiro (2003, p. 25) compreende que é também neste fluxo de ideias, pessoas e grupos sociais que as preocupações ambientais ganham novo "contorno" e o ambientalismo se configura como movimento histórico, período em "que ocorreram movimentos pacifistas, antinucleares, hippie e de contracultura, como resposta ao establishment político norte-americano, autoritário e belicista e a um estilo de vida pautado no consumo de supérfluos". O movimento ambientalista europeu, contudo, não pode ser compreendido como um movimento uno. Segundo Grèze (2003, p. 1), o ambientalismo é portador de várias especificidades de acordo com o país analisado ou a região:

A construção do movimento verde a Oeste se dá essencialmente a partir da luta antinuclear, 
pacifista e associativa, após a "convergência cultural" conquistada com uma parte do mundo sindical e de extrema esquerda. A história da construção do movimento ecologista a leste é totalmente outra. Os verdes vêm dos movimentos cidadãos mobilizados contra o comunismo de Estado: eles nascem na clandestinidade e se desenvolvem apenas após a queda do muro de Berlim.

Classificar o movimento ambientalista em dois blocos também não dá conta da complexidade de trajetórias de cada região e/ou país, a generalização é caricatural. Apenas como exemplo, a leste, a autora destaca grandes diferenças entre a República Tcheca, Romênia, Polônia e Hungria, a história e as diferentes práticas sociais influenciam a construção dos movimentos ambientalistas. Aqui dadas as inserções dos entrevistados, tratam do movimento ambientalista do Oeste Europeu, com mais aproximações com nossa realidade.

Serusiaux comenta que durante a década de 60, época da Guerra Fria, viviam um momento muito delicado, com receio de ataques e terrorismo, e a preocupação das pessoas e movimentos sociais se concentrava na questão da segurança. Segundo ele, neste contexto, o ambiente se tratava de um tema secundário. Entendia que certamente havia relações entre o movimento ambientalista e outros, mas que as associações ambientalistas eram e ainda são até hoje "relativamente distantes dos sindicatos, mais próximas do mundo patronal..." Da mesma forma, ele afirma que o movimento de 68 não se detinha absolutamente sobre "o ambiente".

Outro ambientalista entrevistado, o professor francês Yvan Carlot, reconhece que o movimento ambientalista não tem relações próximas com o movimento dos trabaIhadores, movimentos sindicais ou da educação formal e não formal. Tem relações próximas com a educação informal (pais, etc.) e com pessoas que amam a natureza. Por outro lado ele reconhece que pessoalmente se engajou no movimento ambientalista no final dos anos 60 , junto a uma corrente de movimentos de resistência que tratavam de outras temáticas, como o feminista. Afirma que o movimento ecologista se firma a partir da mesma dinâmica de evolução da sociedade, num momento de "crash" da sociedade francesa. As movimentações de 60 são a demonstração de que a nova geração não se sentia representada pela forma de agir e pensar da sociedade francesa à época. Sobre esta questão, Parmentier, afirma: "Está claro que em seu início, os movimentos ambientalistas são extremamente relacionados aos movimentos sociais e as causas defendidas são múltiplas. Ambos defendem a presença da natureza na sociedade, da mesma forma como se opõem a certas formas de agir, aos autoritarismos e, de maneira ampla, se opõem ao nuclear. Há formas de oposição que tocam em todo tipo de assunto e entre eles, está a questão ambiental. Portanto, quando estudamos os documentos que foram conservados nos arquivos da Etopia ${ }^{7}$, do partido verde, mas também do movimento militante antes deste partido, nós constatamos isso, que as causas de combate são mistas..."

Segundo ela, este processo continua até o final dos anos 60 e início dos anos 70, quando se inicia institucionalização e politização clara do movimento, com a criação de partidos. E ressalta que sobre as relações entre os movimentos sindicalistas, trabalhadores e a questão ambiental há pouquíssimos estudos, o que precisaria ser mais bem esclarecido.

Aos poucos com os depoimentos dos entrevistados vai ficando mais claro que a compreensão sobre o que seja "movimentos sociais da década de 60" é diversa: indo daqueles estritamente ligados aos trabalhadores até os "novos movimentos sociais". Estes se diferenciam dos outros - os movimentos sindicais, ligados à organização social do trabalho e também presentes nas movimentações de 1968 - pelas pautas defendidas, podendo abranger sujeitos de setores e classes sociais diferentes. Outras questões que podem influenciar na compreensão destas relações é a concepção de ambiente que possuem, da função do movimento ambientalista, além de a qual movimento se referem (localidade), etc.

Uma análise mais pormenorizada, a partir das institucionalizações do movimento ambientalista é feita por Benoît Dupret. Segundo ele, as relações mais ou menos próximas entre o movimento ambientalista e os movi- 
mentos sociais podem ser compreendidas no contexto histórico de cada sociedade/ nação. De modo geral, na França, Bélgica, Inglaterra e Alemanha, nascem como resposta à retomada do poder cristão e burguês, na década de 60 (após enfraquecimento da esquerda, sindicatos e partido socialista). Indica, contudo, que há diferentes nuances entre eles: na Bélgica, este movimento buscou inserir suas demandas nos programas de partidos políticos com maior aproximação ideológica, contudo, por não terem suas questões suficientemente consideradas, fundam um partido próprio que, gradualmente, ganha grandes dimensões, e chega à chefia do Parlamento Europeu. São pouco ligados, contudo, aos movimentos sociais - os socialistas -, mas relacionam-se aos movimentos de intelectuais, trabalhadores cristãos, os mais conservadores. Afirma ainda que na Alemanha, onde o movimento verde também se expande consideravelmente, as relações com os movimentos sociais contestatórios são mais próximas, contribuindo com a luta das organizações que estão à margem, "sem tetos" e desempregados, por exemplo. Já na França e Inglaterra, o debate polarizado entre esquerda e direita, trabalhadores e conservadores não possibilita maior desenvolvimento da ecologia na política.

Esta análise pode ser reforçada pelo que afirma Loureiro (2003), o ambientalismo é um movimento, um projeto múltiplo que se inscreve na política mundial, questionando tanto de modo material quanto simbólico o relacionamento entre seres humanos na e com a natureza: desde abordagens anti-humanistas, ecocêntricas e individualistas, com objetivos de ajustar comportamentos para se adaptar a este modelo social, passando por aquelas com atuação pontual e preservacionista a outras mais racionais e coletivistas, com objetivos emancipadores, buscando transformar as relações e o próprio modelo de vida.

De modo geral, nesta era de contestação da sociedade, algumas correntes do movimento ambientalista passam a atuar de maneira diferente, ganham novos debates e combates políticos incorporando novas ideias, questionamentos sobre os modos de vida vigentes, superando as concepções conservacionistas e moralistas. Neste sentido, possuem raízes comuns aos novos movimentos sociais. Mas, sem dúvida, outras não se envolveram com tais ideais e mobilizações, mantiveram sua práxis ou ainda se modificaram ao longo do tempo, por influência de outros fatores.

Embora não haja uma relação direta entre contestações e transformação dos movimentos e da realidade, autores identificam modificações na prática social decorrentes da participação de um conjunto de setores da sociedade mais ou menos relacionados (BRILLANT, 2008, GRÈZE, 2003). Os "novos movimentos sociais" tomam forma nas ruas, mas também na vida da população e no mesmo contexto, os movimentos trabalhador e sindical, já mais experientes e organizados, também presentes, podem ter alavancado a participação dos demais. Parte dos movimentos atuantes neste momento histórico, para superar a lógica de serem apenas grupos de pressão, característica dos movimentos sociais desta época, vai aos poucos se organizando, se institucionalizando. Trata-se da multiplicação de grupos "primários, pequenas células (...) bastante flexíveis, locais, informais" (RIHOUX, 2004, p.32), culminando em associações, sindicatos, partidos políticos, etc., alguns deles ainda atuantes nos dias de hoje, inclusive no âmbito escolar. Estes e outros movimentos sociais que conseguiram se institucionalizar também contribuíram com a formação política da população (IDEM) que segundo Bordenave (1992) trata-se da microparticipação. É neste âmbito que a participação exerce uma função educativa, preparando as pessoas tanto para assumir responsabilidades quanto para exigir mudanças. Segundo ele, a microparticipação nestas instâncias é fundamental à democracia, porque é nelas que verdadeiramente a participação se desenvolve e se amplia. Ao mesmo tempo a participação em nível macro - sociedade global - é alavanca que forma progressivamente os alicerces para mudança na responsabilização e ação das pessoas, individual e coletivamente.

Como consequência deste processo e num contexto mais propício (sem regimes ditatoriais) a participação em diversos países europeus se torna prática mais comum. Além disso, como pudemos observar em diferentes instituições em Liège, na Bélgica, a educação para cidadania e controle social também é ensinada e praticada, como 
ocorre nas disciplinas na formação de professores em e para diferentes níveis e modalidades de ensino que tematizam a história da cidadania, as formas e instrumentos de participação, controle e governança social. Por outro lado, por meio das entrevistas nesta mesma localidade e também na França foi possível notar que a participação social não se relaciona clara e diretamente com a questão ambiental. Ou seja, embora o controle e participação social possam ser mais familiares, pela construção histórica e práticas culturais e embora incentivem, ensinem e participem na prática, o "movimento ambientalista" e nem mesmo a Educação Ambiental (EA) na Bélgica e na França parecem se aproximar e se ocupar normalmente desta questão, segundo nossos entrevistados.

Neste contexto e também em sintonia com as observações de outros membros de um Grupo de Pesquisa em EA nos congressos internacionais e publicação de revistas, ela parece assumir nestes países muitas vezes posições mais próximas das tendências pedagógicas não-críticas (conservadoras) e reprodutivistas (ou crítico-reprodutivistas) ${ }^{8}$, conforme definiu Saviani (2007), até porque a transformação social mais radical não parece ser de interesse coletivo da população destes países.

É neste sentido que compreendemos também que os movimentos sociais contestatórios europeus da década de 60 não são revolucionários, questionavam práticas sociais e formas de pensar, mas não a transformação ampla e para todos, ou seja, a transformação do sistema de produção e organização da vida em sociedade. Frente a tantas mobilizações, pressões do operariado e greves gerais, etc. os donos dos meios de produção se viram obrigados a negociar para sua própria sobrevivência. A conquista não foi resultado apenas das movimentações da década de 60, mas de um processo histórico secular de mudanças na prática social, de participação cada vez mais institucionalizada, de grupos que até então, em sua maioria, apenas assistiam as decisões serem tomadas. "A partir daí começou um processo importante de conquista do espaço do trabalhador na sociedade e no crescimento econômico dos países, que levou à formação de nações com expressiva predominância de estratos médios" (DEMO, 1988, p.14). Mas o capitalismo europeu,
... captou rápido que a formação de amplas classes médias, se aparentemente significaria certa redução das taxas de lucro através do pagamento de melhores salários, por outra produzia os necessários consumidores, além de uma camada conservadora em termos políticos (IDEM, p. 23).

Brillant (2008) ressalta que alguns movimentos após institucionalização e conquista do poder de participação, passam a ser marcados por rigidez, justificada, como de costume, pela necessidade de a população adquirir hábito com as novas formas de pensar e de práticas, não muito diferentes do que houve com a burguesia após a Revolução Francesa.

As mudanças possibilitaram neste sentido uma renovação do sistema capitalista e não a sua transformação: a garantia da manutenção do sistema menos desigual na Europa, com menos exploração das classes trabalhadoras nesses países leva o grande capital a buscar a manutenção das diferenças em outro lugar, entre as nações, recriando a desigualdade agora entre as nações civilizadas do norte e as do sul - "de terceiro mundo" -, para onde a exploração foi então "exportada".

\section{Contestação e crítica no Brasil}

Na década de 60 , outras partes do globo como a América Latina e do Norte vivenciam também movimentos de contestação do status quo. No entanto, no Brasil vivíamos, assim como em outros países, uma ditadura militar, que tolheu e oprimiu pessoas e movimentos ${ }^{9}$. Importa, portanto, compreender como houve a difusão das ideologias e ações em diferentes cantos do globo? Algumas pistas são as influências de figuras que representam uma resistência poderosa como os líderes de Hô Chin Minh, Mao, Castro e Che Guevara, fazendo frente à hegemonia da rígida União Soviética que já não era mais portadora de esperanças (DREYFUS-ARMAND, 2008); os pensadores, ativistas e guerrilheiros brasileiros exilados que ainda mantinham contato com o país por cartas e depois retornam imprimindo em sua atuação e nos grupos que compõem o pensamento crítico que fora apropriado; a evolução das ciências sociais, com destaque para a so- 
ciologia, também pode ter contribuído com este processo de difusão do pensamento crítico, expandindo-se da academia à população; além da contracultura, especialmente o meio musical que, "driblando" a censura, circula ideias entre os países, contribuindo para fortalecer uma cultura comum, sobretudo, a jovem, que desempenhou importante resistência aos regimes ditatoriais. No Brasil, a manifestação cultural desta época é riquíssima, na música, no cinema, no teatro, na literatura, nas artes plásticas, etc., mas também teve contribuição importante o movimento feminista, estudantil, sindical e ligado ao direito da terra.

Não há dúvidas de que houve influências estrangeiras em manifestações que irromperam por aqui (VIOLA e VIEIRA, 1992), mas de forma dialética, com influências mútuas, continuidades e rupturas, aproximações e divergências, enfim, um processo vivo que se materializou por meio de disputas e acordos entre setores poderosos e conservadores e aqueles que desejavam transformar o cenário de concentração de poder, a opressão militar e a resistência popular. Assim, Dreyfus-Armand (2008, p. 26), afirma que o "espontaneísmo antiautoritário" pode ter sido a principal qualidade dos movimentos de contestação nos diferentes países.

Retroalimentam-se ideologias dos movimentos sociais estrangeiros e nacionais, numa terra em que a exploração estava enraizada desde os tempos de colônia, o que, gradualmente foi possibilitando à parcela da população questionar as suas condições de vida, limitada oferta de educação, organizada nos moldes da classe dominante e o direito à participação ativa neste ambiente. Somam a estas questões a demanda colocada pelo sistema econômico que se expandia nas décadas de 50 e 60 e exigia treinamento e qualificação de mão de obra, o que acaba por culminar na reestruturação do sistema educacional. Este expande o seu atendimento que ocorre, contudo, em consonância com os moldes antigos, com projetos muito diferentes entre a educação de uma minoria e a da maioria, uma escola dual. Saviani (2007) afirma que aos trabalhadores é oferecido o mínimo, um conhecimento restrito ao domínio da sua função produtiva, já que não podem ser desapropriados totalmente do saber.
São, contudo, expropriados do saber sobre o conjunto do processo de produção, que é propriedade privada da classe dominante.

Estas análises pretendem demonstrar que as dificuldades efetivas de participação da população, especialmente a população menos favorecida são construídas historicamente, mas ao mesmo tempo, observar que houve avanços conquistados com a luta da população em torno dos seus direitos, ou seja, são injustiças históricas, mas exatamente por serem socialmente construídas, são passíveis de transformação. Porém, análises críticas sobre a história não estão acessíveis a todos, assim não se compreende as injustiças que são o berço da enorme desigualdade que vivemos até hoje. Naturaliza-se a educação pública de má qualidade, como se fosse apenas "defeituosa" e não um projeto para manutenção da ordem das coisas, assim como se naturaliza o capital pautado na acumulação privada - como única forma de organização da sociedade.

Mas, se as condições de vida da maioria da população se tornam cada vez mais precárias, no estágio atual do capitalismo, com a concentração de renda crescente ${ }^{10}$, a exploração da mão de obra do trabalhador e da riqueza da terra e a formação esvaziada da população menos favorecida, são exatamente nestas condições de acirramento das injustiças e com o esforço para compreendê-las no interior da prática social, que despontam as condições e exigências - para que tais questões sejam superadas. A contradição é o signo da mudança e do movimento da história e desvelar a impossibilidade de justiça social, econômica e ambiental dentro da lógica capitalista talvez seja uma das principais contribuições de nações como o Brasil (e outros da América Latina).

Se em alguns países europeus e em outros países mais favorecidos a Educação Ambiental se relaciona timidamente à cidadania e ao questionamento do modelo de organização social, estando mais voltada à conservação de áreas verdes, espécies ameaçadas e à gestão dos recursos naturais para manutenção do mesmo sistema, no Brasil, a partir da década de 80 e progressivamente, a Educação Ambiental se aprofunda e se fortalece junto 
ao movimento crítico da Educação. O que os identifica é a crítica ao modelo de vida exploratório e a busca por alternativas, por meio da formação plena dos sujeitos para a participação efetiva na construção de uma sociedade mais justa e sustentável. A escola, neste contexto, é local potencial que pode garantir o acesso aos elementos culturais essenciais, conteúdos que possibilitem a humanização dos sujeitos: pensar criticamente a realidade e participar ativamente neste ambiente, de maneira organizada (SAVIANI, 2007).

\section{Educação Ambiental Histórico-Crítica: conside- rações sobre a formação participativa}

Compreendemos que a educação ambiental é antes de tudo educação e por fundar-se em escolhas e projetos de sociedade, é política. Baseia-se numa concepção de homem, que se forma numa sociedade de classes diferentes e de interesses antagônicos e, por isso, cheia de contradições. É este cenário que define a inserção e a relação dos homens e mulheres no ambiente.

A educação ambiental brasileira produziu-se com ingredientes peculiares: uma combinação de ideias já defendidas no estrangeiro, amadurecidas, e outras ideias revolucionárias gestadas no seio de nossa sociedade, com base no pensamento crítico que foi e ainda está sendo produzido, de forma a compreendermos e enfrentarmos esta realidade, ou seja, trata-se de uma práxis participativa, em que se articulam pensamento e ação, teoria e prática. Assumimos, portanto, a educação ambiental relacionada à justiça, emancipação, participação social e sustentabilidade, abordando as temáticas de maneira contextualizada, o que gradualmente vai imprimindo uma identidade mais crítica à educação ambiental brasileira.

Não é raro, porém, observar no Brasil, práticas educativas ambientais conservacionistas e moralistas, responsabilizando os sujeitos, individualmente, pela degradação e insustentabilidade. Compreendemos que tal visão dissimula os reais conflitos relacionados à questão ambiental. Mas, a concepção crítica se expande e encontra neste solo condições para frutificar:
Não é por acaso que 50,2\% dos programas analisados pelo Levantamento Nacional de Projetos de Educação Ambiental adotam a elaboração de projetos de participação comunitária como método utilizado (MMA, 1997); também não é por acaso que o novo universo vocabular ambientalista apontado por Crespo et al (1998), conta com termos como cidadania ativa, descentralização ou gestão participativa. Da mesma forma, não é por acaso que um dos consensos da comunidade ambientalista brasileira é de que só a democracia levará à sustentabilidade, através da criação de espaços de negociação e do fortalecimento dos instrumentos já existentes, como os órgãos colegiados, a exemplo dos Conselhos de Meio Ambiente e as instâncias participativas consultivas, como as Audiências Públicas (LAYRARGUES, 2015, p. 06).

Mas, o pensamento e posicionamento críticos da educação ambiental brasileira se restringirão tão somente à reflexão sobre a realidade injusta se tais ideais não forem colocados a serviço da melhoria da vida das pessoas, se não atingirem e contribuírem com as formas de pensar e ser das pessoas. Neste sentido, as ideias progressistas precisam chegar às massas para que compreendam a urgência e a imprescindibilidade da organização da sociedade em torno de seus interesses, transformando as formas atuais e construindo outras diferentes. Também será teoria inócua a teoria que, parada no tempo não avançar com a reflexão contínua e sistematizada sobre as suas aplicações.

Com estas preocupações, há alguns anos, procuramos individual e coletivamente, junto a um Grupo de Pesquisa em Educação Ambiental, nos aprofundar no estudo do pensamento crítico, mais especificamente no materialismo histórico dialético (MHD) como método de interpretação da realidade, Junto a outros grupos parceiros vem-se organizando eventos também em busca de aprofundar e fomentar a discussão da Educação Ambiental crítica.

Além disso, a Pedagogia Histórico-crítica também fundamenta os processos educativos e reflexões que desenvolvemos, levando-nos a denominar esta aproximação de Educação Ambiental Histórico-Crítica (JUNQUEIRA, 
2014). Acreditamos que tal aproximação e parceria podem oferecer subsídios que contribuam para processos de pesquisa e processos formativos, que destaquem e promovam a humanização dos sujeitos, condição e resultado da participação política com o objetivo de transformação das relações em sociedade na e com a natureza, relacionando a educação ambiental com a educação escolar e formação de professores.

Neste sentido, sob o enfoque Histórico-crítico da EA compreendemos que a exploração da natureza relaciona-se intimamente com exploração dos homens pelos próprios homens. A mudança deste cenário requer desenvolver processos educativos que possibilitem aos sujeitos compreenderem a realidade socioambiental em seus múltiplos fatores, desvelando as contradições persistentes nas relações em sociedade, bem como seu movimento constante, para não apenas fazerem parte deste contexto, mas para tomarem parte nas questões que são do interesse de todos nós e são decididas por poucos.

\section{Notas}

1 Especial agradecimento à CAPES pela bolsa de doutoramento sanduíche concedida.

2 Neste sentido, a obra de Eugène Huzar, em 1855: O fim do mundo pela ciência traz uma crítica ao progresso ilimitado e imediato e à ciência como forças que, em conjunção, abrem livre caminho para o poder da indústria (CARNINO, 2009). O livro teve várias edições, o que pode demonstrar a inquietação e sensibilidade da população em relação aos impactos causados pelo desenvolvimento industrial à época.

3 Emmanuël Serusiaux, professor da Universidade de Liège, Bélgica, militante ambientalista desde a década de 60 e presidente de uma importante associação belga de proteção da natureza, com 16 mil membros, Natagora.

4 Isabelle Parmentier é professora da Universidade de Namur, Bélgica e responsável pelo polo de História Ambiental desta Universidade.

5 Yvan Carlot (Lyon, França) professor de Geografia aposentado, envolvido com o Movimento Ambientalista francês há muitas décadas e membro atuante de diferentes associações, de bairro a ONGs ambientalistas.

6 Benoir Dupret (Tilff, Bélgica), ativista ambiental e colaborador na conformação inicial do Partido Verde - Écolo - na Bélgica. No momento da entrevista já se encontrava afastado do grupo.

7 ONG mantida por membros e simpatizantes do Movimento Ambientalista e Partido Verde - Écolo.

8 Tais observações vêm sendo realizadas por integrantes de um Grupo de Pesquisa desde 2009, no VI Congresso Íbero Americano de Educação Ambiental, em San Clemente de Tuyu, posteriormente no mesmo ano, no Congresso Mundial de Educação Ambiental, em Montreal, em Varadero, Cuba, em 2011 e depois em 2013 em Marrakech, além dos eventos brasileiros de Educação Ambiental em que há publicações de autores de outros países.

90 memorial da Resistência, localizado no antigo DEOPS (Departamento de Ordem Política e Social que foi muito atuante no Estado Novo e no Regime Militar de 1964) possui ótimo acervo fixo e itinerante além de diversos cursos sobre esta fase sombria de nossa história.

10 De acordo com matéria da BBC News, "a riqueza acumulada pelo $1 \%$ mais abastado da população mundial agora equivale, pela primeira vez, à riqueza dos $99 \%$ restantes", dados indicados pela Oxfam, ONG engajada no combate da pobreza.

\section{Referências}

BORDENAVE, J E. D. O que é participação? São Paulo: Brasiliense, 1992.

BOURG, D. A Profundidade histórica dos problemas ambientais. Universidade virtual ambiente e desenvolvimento sustentável, Universidade Lauvanne, França. https://www. youtube.com/watch?v=Rd9ONcVUcuo, acesso em: junho de 2016.

BRILLANT, B. La contestation das tous ses états in DREYFUS-ARMAND, G; FRANK, R; LEVY, M-F; ZANCARINI-FOURNEL, M. Les années 68: Le temps de la contestation. Editions Complexe: Paris, 2008

CARNINO, G. E.H. La Fin du monde par la science. Documents pour I'histoire des techniques, 2009. Disponível em : http://dht. revues.org/608. Acesso em: agosto 2016.

CARVALHO, Isabel Cristina M. Educação Ambiental Crítica: Nomes e Endereçamentos da Educação in Identidades da Educação Ambiental. Brasília - DF: Ministério do Meio Ambiente, 2004

DEMO, P. Participação é conquista: noções de política social participativa. São Paulo: Cortez: Autores Associados, 1988.

Pesquisa Participante: saber pensar e intervir juntos. Brasília-DF: Liber Livro Editora, 2001.

DREYFUS-ARMAND, G.. L'espace et le temps des mouvements de contestation in DREYFUS-ARMAND, G; FRANK, R; LEVY, M-F; ZANCARINI-FOURNEL, $M$. Les années 68: Le temps de la contestation. Editions Complexe: Paris, 2008.

ETOPIA, Charte des Verts européens, Lignes directrices du parti Vert européen, 2006, Genève, Partie 5: Une Histoire de L'écologie en 4 manifestes in L'écologie politique se manifeste, Revue 12, 2006. Disponível em: http://www.etopia.be/spip. php?rubrique516, acesso em dezembro de 2013.

FRANK, R. Introduction in DREYFUS-ARMAND, G; FRANK, R.; LEVY, M-F; ZANCARINI-FOURNEL, M. Les années 68: Le temps de la contestation. Editions Complexe: Paris, 2008. 
GALEANO, E.H. As Veias Abertas da América Latina. Coleção L\&PM Pocket v. 900 Porto Alegre, RS, 2011.

GRÈZE, C. La construction de la gauche écologiste : un mythe ? La realité d'un chemin difficile. Ecorev - Revue critique d'écologie politique, n. 14, automne 2003. Disponível em http://ecorev.org/spip.php?article199, acesso em: novembro 2013.

JACOBI, P. Participação. In: FERRARO-JR, L.A. (coord). Encontros e Caminhos: Formação de Coletivos Educadores e Educadoras Ambientais/ Ministério do Meio Ambiente. Diretoria de Educação Ambiental; Brasília: Ministério do Meio Ambiente, 2005.

JUNQUEIRA, J.N. Por uma educação ambiental histórico-crítica. 2014, 144f., Tese (doutorado em Educação para a Ciência). Faculdade de Ciências, Universidade Estadual Paulista, Campus de Bauru, UNESP, Bauru - SP.

LAYRARGUES, P.P. Educação para a gestão ambiental: a cidadania no enfrentamento político dos conflitos socioambientais. Disponível em http://www.plataformademocratica.org/Publicacoes/7103_Cached.pdf, acesso em: julho 2015.

LOUREIRO, C.F.B. O movimento ambientalista e o pensamento crítico: uma abordagem política. Rio de Janeiro - RJ: Quartet, 2003.

NOVICKI, V. Práxis: problematizando consciência e participação na educação ambiental brasileira in LOUREIRO, C. F. B. A Questão Ambiental no Pensamento Crítico: Natureza, Trabalho e Educação, Rio de Janeiro: Quartet, 2007.

ORELLANA, I., FAUTEUX, S. L'éducation relative à I'environnement: à travers les grands moments de son histoire. Université du Québec à Montréal Environnement Canada - Passons à l'action pour l'environnement. Communication présentée lors du Colloque du 19-30/10/98 à Montréal L'avenir de l'éducation relative à l'environnement dans un monde postmoderne ? Texte atualisé en 2007.

REUBEN, A. $1 \%$ da população global detém mesma riqueza dos $\mathbf{9 9 \%}$ restantes, diz estudo. BBC News. Disponível em http://www.bbc.com/portuguese/noticias/2016/01/160118_ riqueza_estudo_oxfam_fn, 18 jan.2016. Acesso em: fevereiro 2016.

RIHOUX, Benoit. Partis politiques et mouvements sociaux: d'où venons-nous, où allons-nous? La Revue nouvelle, $n^{\circ} 3$, mars. 2004, p. 24-37.

SAVIANI, D. Escola e Democracia, 39a Ed., Campinas, SP: Autores Associados, 2007.

SEVCENKO, N: A imaginação no poder e a arte nas ruas. In Itaú Cultural. (Org.). Anos 70: trajetórias. São Paulo: Iluminuras, 2006, p. 13-25.

TOZONI-REIS, M. F. C (Org.) A pesquisa-ação-participativa em educação ambiental: reflexões teóricas, São Paulo: Annablume; FAPESP; Botucatu: Fundibio, 2007.
TREIN, E.S. A Educação Ambiental Crítica: crítica de que? Revista Contemporânea de Educação, vol. 7, n. 14, agosto/dezembro de 2012.

TREBITSCH, M. Voyages autour de La révolution. Les circulations de la pensée critique de 1956 à 1968. DREYFUSARMAND, Geneviève. L'espace et le temps des mouvements de contestation in DREYFUS-ARMAND, Geneviève; FRANK, Robert; LEVY, Marie-Françoise; ZANCARINI-FOURNEL, Michelle. Les années 68: Le temps de la contestation. Editions Complexe: Paris, 2008.

VIOLA, E. J, VIEIRA, P. F. Da preservação da natureza e do controle da poluição ao desenvolvimento sustentável: um desafio ideológico e organizacional ao Movimento Ambientalista no Brasil. Rev. Adm Pública, out. Dez. 1992, 26 (4). Rio de Janeiro, RJ. Pág- 81-104.

Recebimento em 19 de junho de 2017.

Aceito em 30 de outubro de 2017. 
